\title{
Coaxial Tubing Systems Increase Artificial Airway Resistance and Work of Breathing
}

\author{
Christin Wenzel MSc, Stefan Schumann PhD, and Johannes Spaeth MD MSc
}

\begin{abstract}
BACKGROUND: Tubing systems are an essential component of the ventilation circuit, connecting the ventilator to the patient's airways. Coaxial tubing systems incorporate the inspiratory tube within the lumen of the expiratory one. We hypothesized that by design, these tubing systems increase resistance to air flow compared with conventional ones. METHODS: We investigated the flow-dependent pressure gradient across coaxial, conventional disposable, and conventional reusable tubing systems from 3 different manufacturers. Additionally, the additional work of breathing and perception of resistance during breathing through the different devices were determined in 18 healthy volunteers. RESULTS: The pressure gradient across coaxial tubing systems was up to 6 times higher compared with conventional ones $\left(1.90 \pm 0.03 \mathrm{~cm} \mathrm{H}_{2} \mathrm{O}\right.$ vs $0.34 \pm 0.01 \mathrm{~cm} \mathrm{H}_{2} \mathrm{O}$, $P<.001)$ and was higher during expiration compared with inspiration $(P<.001)$. Additional work of breathing and perceived breathing resistance were highest in coaxial tubing systems, accordingly. CONCLUSIONS: Our findings suggest that the use of coaxial tubing systems should be carefully considered with respect to their increased resistance. Key words: mechanical ventilation; devices/equipment; development and evaluation/technology assessment; artificial airways; breathing system; airway resistance; work of breathing. [Respir Care 2017;62(9):1171-1177. (C 2017 Daedalus Enterprises]
\end{abstract}

\section{Introduction}

During mechanical ventilation, the tubing system links the ventilator to the patient's secured airways. Conventionally, 2 silicone tubes separate inspiratory and expiratory flow. Over the past years, disposable plastic tubes have been used increasingly, to cope with the growing demands on hygiene and cost/value ratio. Coaxial tubing

\footnotetext{
The authors are affiliated with the Department of Anesthesiology and Critical Care, Medical Center, University of Freiburg, Faculty of Medicine, University of Freiburg, 79106 Freiburg, Germany.
}

This study was supported by departmental funding. The authors have disclosed no conflicts of interest.

Ms Wenzel presented a version of this paper at the Deutscher Anästhesie Congress, held April 14-16, 2016, in Leipzig, Germany, and at BMT 2016, held October 4-6, 2016, in Basel, Switzerland.

Correspondence: Johannes Spaeth MD MSc, Department of Anesthesiology and Critical Care, Medical Center, University of Freiburg, Hugstetter Strasse 55, 79106 Freiburg, Germany. E-mail: johannes. spaeth@uniklinik-freiburg.de.

DOI: $10.4187 /$ respcare. 05426 systems incorporate the inspiratory tube inside the lumen of the expiratory tube (Fig. 1). Coaxial tubing systems may provide facilitated handling during anesthesia and gas temperature exchange across the inner laying surface. ${ }^{1}$ However, little is known about the resistive behavior of such tubing systems. Studies investigating other components of the artificial airways found the cross-sectional area to be the most relevant determinate for the components' resistance to air flow. ${ }^{2,3}$ Considering these findings, coaxial tubing systems may increase resistance to air flow, because their design is at the expense of the lumina's cross-sectional area.

We hypothesized that resistance, additional work of breathing, and perceived breathing resistance are higher in coaxial tubing systems compared with conventional ones. Therefore, we quantified the pressure-flow characteristics of coaxial and conventional disposable or reusable tubing systems from 3 different manufacturers. Furthermore, additional work of breathing and perception of breathing resistance were determined in healthy volunteers.

\section{Methods}

Coaxial tubing systems and conventional disposable tubing systems (including a Y-piece and a $90^{\circ}$ connector) 


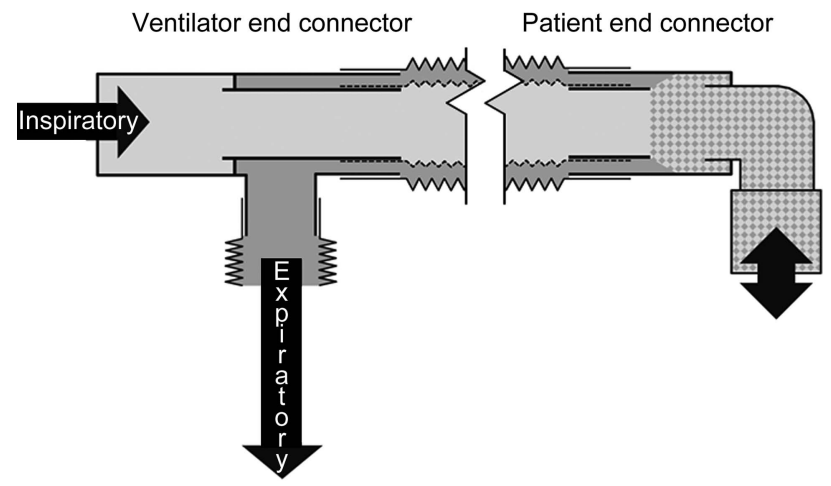

Fig. 1. Technical scheme of coaxial tubing systems, given for 2 different sections. At the tubing's ventilator end, a rigid T-piece connector enables inspiratory (light gray area) and expiratory gas flow (dark gray area) to pass each other. At the patient end, the inspiratory lumen ends freely within the expiratory lumen, thereby mixing the gas flow (shaded area). Please note that the inspiratory tube, which is lying on the inside, is held in position at the ends only.

Table 1. Specifications of Tubing Systems

\begin{tabular}{|c|c|c|c|}
\hline Tubing Systems & REF & $\begin{array}{l}\text { Length } \\
\text { (insp./exp.) } \\
\text { (cm) }\end{array}$ & $\begin{array}{c}\text { CSA } \\
\text { (insp./exp.) } \\
\left(\mathrm{mm}^{2}\right)\end{array}$ \\
\hline \multicolumn{4}{|l|}{ Conventional reusable TS } \\
\hline Silicone (VBM) & $66-22-180$ & $180 / 180$ & 346 \\
\hline +Y-piece (VBM) & $60-11-200$ & NA & 177 \\
\hline$+90^{\circ}$ connector $(\mathrm{VBM})$ & $60-12-000$ & NA & 177 \\
\hline \multicolumn{4}{|l|}{ Conventional disposable TS } \\
\hline Dräger & МР00349 & $180 / 180$ & 380 \\
\hline Covidien & 301NP14325 & $180 / 180$ & 314 \\
\hline Medisize & 5017A114 & $150 / 150$ & 346 \\
\hline \multicolumn{4}{|l|}{ Coaxial TS } \\
\hline Dräger (VentStar) & MP00356 & $180 / 240$ & $201 / 169$ \\
\hline Covidien (DUO) & $285 / 25557$ & $200 / 250$ & $154 / 225$ \\
\hline Medisize (UNI LIM) & $5017 \mathrm{~K} 6884$ & $180 / 250$ & $177 / 225$ \\
\hline $\begin{array}{l}\text { The air-streamed cross-sectional areas o } \\
\text { calculated based on the difference of th } \\
\text { diameter of the inlaying tube. } \\
\text { REF = manufacturer's reference numbe } \\
\text { insp. = inspiratory } \\
\text { exp. }=\text { expiratory } \\
\text { CSA = cross-sectional area } \\
\text { TS = tubing system } \\
\text { NA = not applicable }\end{array}$ & $\begin{array}{l}\text { the coaxial tubing } \\
\text { inner diameter of } \mathrm{t}\end{array}$ & $\begin{array}{l}\text { ystems' expirator } \\
\text { ee outlaying tube }\end{array}$ & $\begin{array}{l}\text { lumina were } \\
\text { nd the outer }\end{array}$ \\
\hline
\end{tabular}

from 3 different manufacturers (Dräger Medical, Lübeck, Germany; Medisize, Siegburg, Germany; and Covidien, Neustadt/Donau, Germany, respectively) were investigated. As a reference, we additionally investigated a conventional reusable tubing system composed of 2 silicone breathing tubes, a Y-piece, and a $90^{\circ}$ connector (all from VBM Medizintechnik GmbH, Sulz am Neckar, Germany). Types, full lengths, and cross-sectional areas of the tubing systems are specified in Table 1.

\section{QUICK LOOK}

\section{Current knowledge}

All components of artificial airways contribute to artificial airway resistance, mainly depending on the inner diameter and the length of the respective device as well as on the present flow. Significant contribution to airway resistance has been shown for endotracheal and tracheostomy tubes but also for heat and moisture exchangers and humidifiers. High artificial airway resistance prolongs expiration time during controlled ventilation and increases the patient's work of breathing during spontaneous breathing. Therefore, artificial airway resistance should be as low as possible.

\section{What this paper contributes to our knowledge}

This study compared the resistances of recently introduced coaxial tubing systems (consisting of 2 interleaved tubes) with conventional tubing systems (consisting of 2 separate tubes) of a disposable or reusable type. Coaxial tubing systems exhibited a significant higher flow-dependent pressure gradient, particularly in expiration, when compared with conventional ones. Similarly coaxial tubing systems increased work of breathing to a relevant extent. Coaxial tubing systems should be carefully applied with regard to their increased resistance.

\section{Pressure-Flow Characteristics}

Pressure-flow characteristics were measured by streaming the tube under test with a defined gas flow (Fig. 2). To generate a reproducible curvature of the respective tube, it was mounted with a defined sagging of $33 \%$ of its total length. When applicable, foldable tubes were measured at their full lengths (Table 1). To cover a clinically relevant flow range, the model was streamed with a sinusoidal flow of $\pm 1.2 \mathrm{~L} / \mathrm{s}$ using a piston pump driven by a control unit (E1100, LinMot, Spreitenbach, Switzerland). Flow (V்) was measured using a pneumotachograph (Fleisch 2, Dr Fenyves \& Gut, Hechingen, Germany) connected to a differential pressure transducer (CP 100, Hoffrichter, Schwerin, Germany). Airway pressures were measured at both ends of the respective tubing system using piezoresistive pressure transducers (Type 4, SI-Special Instruments GmbH, Nördlingen, Germany). Proximal and distal pressure measuring sites were of identical inner diameter to prevent the Bernoulli effect from influencing the measurements. All instruments were calibrated daily before the beginning of the experiments, after interruption of an experiment exceeding $1 \mathrm{~h}$, or after a visible offset in baseline values. 


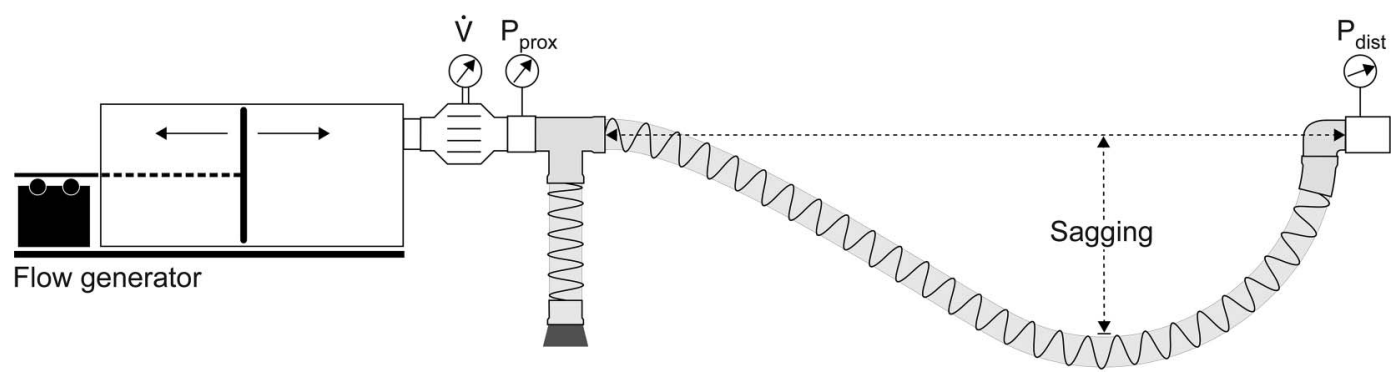

Fig. 2. Flow model, exemplarily shown for measurements across the inspiratory lumen of a coaxial tubing system. Sinusoidal flow was applied using a piston pump driven by a linear motor (Flow generator). Flow (V) was measured at the tubing system's ventilator end. Airway pressures were measured at the proximal $\left(P_{\text {prox }}\right)$ and the distal end $\left(P_{\text {dist }}\right)$ of the tubing system. Please note that the tube's sagging was standardized to $33 \%$ of the total length.

We calculated the flow-dependent pressure gradient across the tubing systems $(\Delta \mathrm{P})$ by means of Rohrer's approach, ${ }^{2}$ reflecting originally a linear and a quadratic relation between flow and pressure gradient. In preliminary experiments, we found that in tubing systems, the linear term does not contribute to $\Delta \mathrm{P}$ to any relevant extent. Therefore, we used a simplified equation containing only the coefficient of the quadratic flow term $\left(\mathrm{K}_{2}\right)$ and inertance (I). ${ }^{3}$

$$
\Delta \mathrm{P}=\mathrm{K}_{2} \times \dot{\mathrm{V}}^{2}+\mathrm{I} \times \ddot{\mathrm{V}}
$$

From the continuously measured $\Delta \mathrm{P}$, flow, and derived volume acceleration $(\ddot{V}), K_{2}$ and inertance I were determined for each tubing system by linear regression of Equation 1. For easier comparison between the different tubing systems, $\Delta \mathrm{P}$ was calculated for an exemplary flow of $600 \mathrm{~mL} / \mathrm{s}\left(\Delta \mathrm{P}_{600}\right)$.

All measurements were performed for each lumen separately and repeated 6 times after dismantling and reassembling of the model setup. Flow and pressure signals were sampled at a rate of $200 \mathrm{~Hz}$. Twelve ventilation cycles were recorded for each condition.

\section{Additional Work of Breathing}

To quantify the tubing systems' load for a patient, we determined the additional work of breathing caused by the tubing systems during quiet breathing. In addition, to investigate whether differences in breathing resistance between the different tubing systems would be of clinical relevance, we evaluated the perception of tubing resistance in healthy volunteers when breathing via the different types of tubing systems. The study was approved by the ethics committee of the University of Freiburg, and written informed consent was obtained by each volunteer before the experiments. Eighteen volunteers (female, $n=5$; male, $n=13$; age, mean [range] $37 \mathrm{y}$ [24-62 y]; weight, mean [range] $76 \mathrm{~kg}$ [54-125 kg]; height, mean [range] $176 \mathrm{~cm}$
[162-192 cm]) with no known history of lung disease were asked to breathe via a mouthpiece through a pneumotachograph (as above). Initially, 20 quiet breaths were taken in a sitting position without any tubing attached to the measurement system.

To eliminate effects of breathing variability during the different trials and to prevent adaptation of the breathing pattern in response to the current load, additional work of breathing (WOB) was calculated instead of directly measured. Additional WOB was calculated from the data measured during the subjects' quiet breathing (without tubing) by integrating the product of $\Delta \mathrm{P}$ and $\dot{\mathrm{V}}$ over the time (t) of 1 min. $^{4}$

$$
\text { Additional WOB }=\int \Delta \mathrm{P} \times \dot{\mathrm{V}} \mathrm{dt}
$$

For that purpose, $\Delta \mathrm{P}$ was calculated from the measured flow and the previously determined respective $\mathrm{K}_{2}$ and I, following Equation 1. Additional WOB/L of ventilation was calculated by dividing additional WOB by minute ventilation. $^{5}$

\section{Perceived Breathing Resistance}

After the initial measurement, a conventional, a disposable, and a coaxial tubing system (the latter two from Dräger Medical) were attached successively to the measuring system, and the volunteers were asked to take another 20 breaths through each device, respectively. To achieve directed flow within the tubing systems, their ends were connected to passive inspiration and expiration valves (resistance $<0.7 \mathrm{~cm} \mathrm{H}_{2} \mathrm{O} \times \mathrm{s} / \mathrm{L}$ at $1.0 \mathrm{~L} / \mathrm{s}$ ). The tubing systems were presented in randomized order, blinded to the volunteers who were given a 1-min rest between 2 consecutive tests. Subsequently, the volunteers were asked to specify the one tubing system they had perceived to provide the highest breathing resistance, respectively. 
Table 2. Rohrer Coefficient $\mathrm{K}_{2}$, Inertance, and Compliance of Tubing Systems

\begin{tabular}{|c|c|c|c|c|}
\hline \multirow{2}{*}{ Tubing Systems } & \multicolumn{2}{|c|}{$\mathrm{K}_{2}\left(\mathrm{~cm} \mathrm{H}_{2} \mathrm{O} \times \mathrm{s}^{2} / \mathrm{L}^{2}\right)$} & \multirow{2}{*}{$\begin{array}{c}\text { Inertance } \\
\left(\mathrm{cm} \mathrm{H}_{2} \mathrm{O} \times \mathrm{s}^{2} / \mathrm{L}\right)\end{array}$} & \multirow{2}{*}{$\begin{array}{l}\text { Compliance } \\
\left(\mathrm{mL} / \mathrm{cm} \mathrm{H}_{2} \mathrm{O}\right)\end{array}$} \\
\hline & Inspiratory & Expiratory & & \\
\hline \multicolumn{5}{|c|}{ Conventional reusable TS } \\
\hline VBM & $1.40 \pm 0.01$ & $-0.94 \pm 0.01$ & $0.09 \pm 0.01$ & $0.63 \pm 0.01$ \\
\hline \multicolumn{5}{|c|}{ Conventional disposable TS } \\
\hline Dräger & $1.42 \pm 0.01$ & $-1.40 \pm 0.01$ & $0.07 \pm 0.01$ & $1.14 \pm 0.03$ \\
\hline Covidien & $1.41 \pm 0.01$ & $-1.27 \pm 0.01$ & $0.08 \pm 0.01$ & $1.43 \pm 0.01$ \\
\hline Medisize & $1.10 \pm 0.01$ & $-0.94 \pm 0.01$ & $0.06 \pm 0.01$ & $0.70 \pm 0.01$ \\
\hline \multicolumn{5}{|l|}{ Coaxial TS } \\
\hline Dräger & $3.19 \pm 0.01$ & $-5.28 \pm 0.03$ & $0.14 \pm 0.01$ & $1.76 \pm 0.09$ \\
\hline Covidien & $4.28 \pm 0.06$ & $-4.99 \pm 0.04$ & $0.17 \pm 0.01$ & $1.39 \pm 0.02$ \\
\hline Medisize & $3.85 \pm 0.01$ & $-4.76 \pm 0.04$ & $0.12 \pm 0.01$ & $1.93 \pm 0.20$ \\
\hline $\begin{array}{l}\mathrm{K}_{2}=\text { Rohrer coefficient for } \mathrm{no} \\
\mathrm{TS}=\text { tubing system }\end{array}$ & & & & \\
\hline
\end{tabular}

\section{Statistical Analysis}

Data are presented as means \pm SD if not indicated otherwise. Pressure and flow measurements were recorded using LabView 7.1 (National Instruments, Austin, Texas) and analyzed using MATLAB 2014.R1 (The MathWorks, Natick, Massachusetts). For comparisons of $\Delta \mathrm{P}_{600}$, ordinary one-way analysis of variance was calculated, followed by Sidak post hoc tests if appropriate (GraphPad PRISM 6.02, GraphPad Software, La Jolla, California). The number of volunteers was calculated in an a priori power analysis based on a chi-square test. From our experimental findings, we expected a very large effect size of 0.75 . Under this assumption, 18 subjects were required to achieve a power of 0.8 for identifying a difference in breathing resistance between the 3 types of tubing systems. For comparison of additional WOB, one-way analysis of variance was calculated, followed by the Dunnett multiple-comparisons test. The ratings for breathing resistance were compared using the Kruskal-Wallis test, followed by Dunn tests. A $P$ value $<.05$ was considered significant.

\section{Results}

\section{Pressure-Flow Characteristics}

Measured pressure gradients were nonlinearly flow-dependent across all devices, increasing disproportionally with increasing flow. Derived resistive coefficients $\mathrm{K}_{2}$ differed between the investigated tubing systems (Table 2). The coaxial tubing systems showed the highest $\mathrm{K}_{2}$ values, whereas the conventional reusable tubing system exhibited the lowest ones. The pressure-flow characteristics varied considerably between the different types of tubing sys- tems. $\Delta \mathrm{P}$ of coaxial tubing systems exceeded considerably $\Delta \mathrm{P}$ of conventional tubing systems (Fig. 3). $\Delta \mathrm{P}$ was comparable during inspiration and expiration in conventional tubing systems but higher during expiration than during inspiration in all coaxial tubing systems (Fig. 3). Among coaxial tubing systems, those of Covidien showed the highest whereas those of Dräger showed the lowest $\Delta \mathrm{P}$ during inspiration. Those of Dräger showed the highest and those of Medisize showed the lowest $\Delta \mathrm{P}$ during expiration. $\Delta \mathrm{P}_{600}$ of the coaxial tubing systems amounted up to $1.90 \pm 0.03 \mathrm{~cm} \mathrm{H}_{2} \mathrm{O}$, whereas it was $<0.51 \pm 0.01 \mathrm{~cm} \mathrm{H}_{2} \mathrm{O}$ (disposable) and $<0.34 \pm 0.01 \mathrm{~cm} \mathrm{H}_{2} \mathrm{O}$ (reusable) in conventional tubing systems $(P<.001)$. Among conventional disposable tubing systems, $\Delta \mathrm{P}_{600}$ was lower in Medisize $\left(0.40 \pm 0.01 \mathrm{~cm} \mathrm{H}_{2} \mathrm{O}, P<.001\right)$ compared with Covidien $\left(0.51 \pm 0.01 \mathrm{~cm} \mathrm{H}_{2} \mathrm{O}\right)$ and Dräger $\left(0.51 \pm 0.01 \mathrm{~cm} \mathrm{H}_{2} \mathrm{O}\right)$. Inertance was $<0.17 \mathrm{~cm} \mathrm{H}_{2} \mathrm{O} \times \mathrm{s}^{2} / \mathrm{L}$ in all devices (Table 2).

\section{Additional Work of Breathing and Perceived Breathing Resistance}

Different types of tubing systems caused significantly different amounts of additional WOB (Fig. 4). Mean additional WOB accounted for up to $3.5 \pm 1.7 \mathrm{~J} / \mathrm{min}$ in coaxial but only $1.0 \pm 0.5$ and $0.8 \pm 0.4 \mathrm{~J} / \mathrm{min}$ in disposable and reusable conventional tubing systems, respectively $(P<.001)$. Additional $\mathrm{WOB} / \mathrm{L}$ caused by the coaxial tubing systems amounted up to $0.3 \pm 0.1 \mathrm{~J} / \mathrm{L}$ and was significantly higher $(P<.001)$ compared with the conventional disposable and reusable ones (Fig. 4). Mean (range) tidal volume was $1.1 \mathrm{~L}(0.4-2.3 \mathrm{~L})$; mean (range) breathing frequency was 13 breaths/min $(8-20$ breaths/min).

Rating of breathing resistance depended on the tubing system used. Of the 18 volunteers, 13 rated breathing resistance of the coaxial tubing system the highest compared 


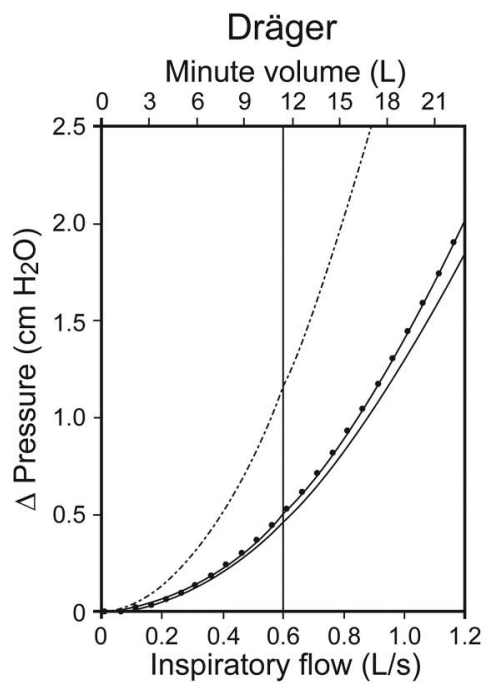

Dräger

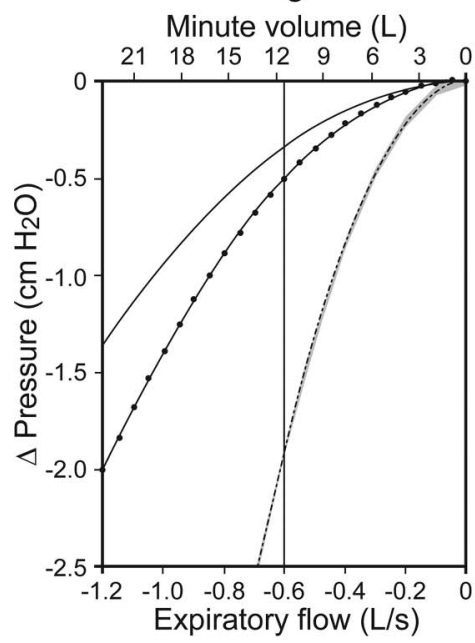

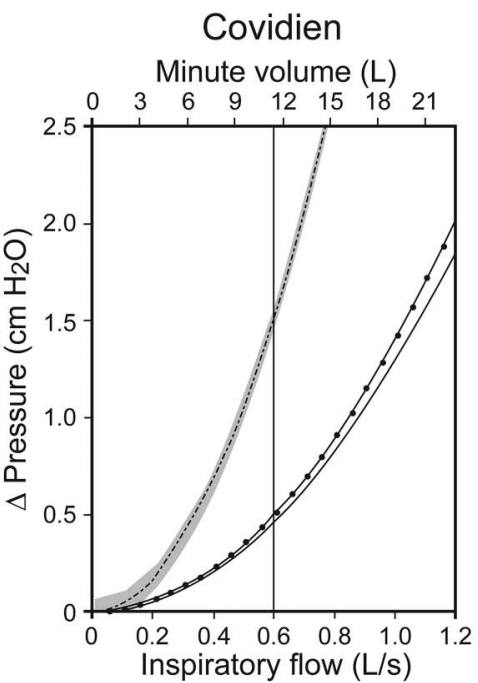

Covidien

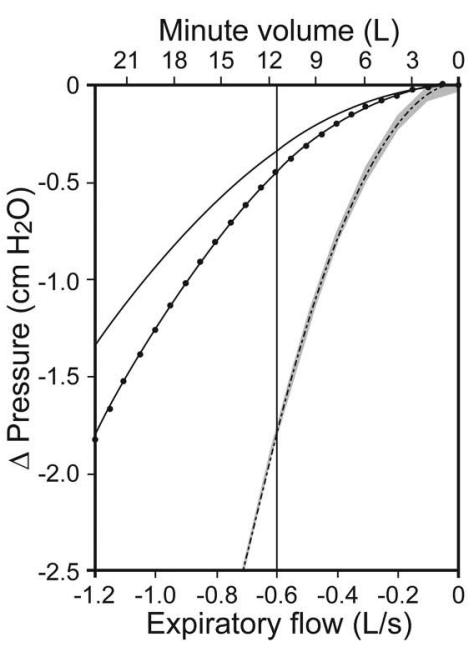

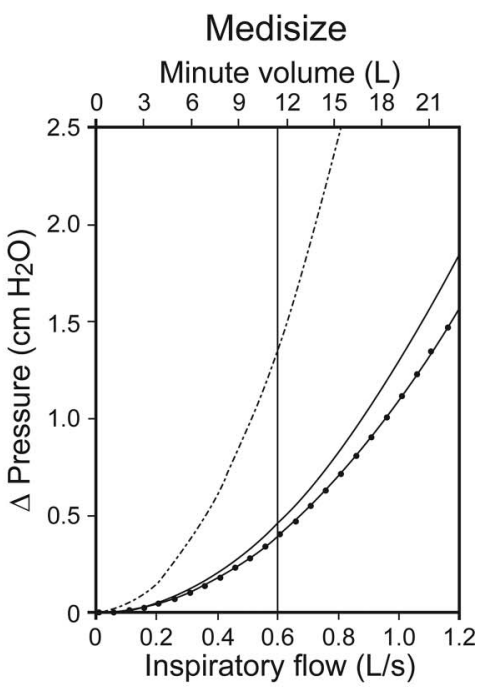

Medisize

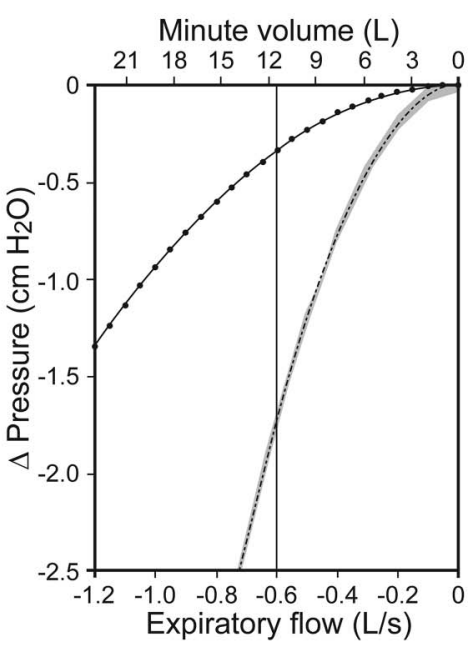

Fig. 3. Flow-depending pressure gradients $(\Delta \mathrm{P})$ across coaxial tubing systems (dashed lines), conventional disposable tubing systems (dotted lines), and a conventional reusable tubing system (solid lines). Curves were calculated from the respective resistance coefficients for the displayed flow range separately for inspiratory flow and expiratory flow and 3 different manufacturers. Gray areas represent SD. The Medisize conventional disposable and reusable tubing systems showed identical progression curves during expiration. Minute volume with peak flow corresponding to flow mentioned in the scale above, assuming a sinusoidal flow profile.

with conventional reusable and disposable tubing systems (both $P<.001$ ). The perception of breathing resistance with conventional reusable and conventional disposable tubing systems did not differ significantly $(P=.40)$.

\section{Discussion}

The main findings of the present study can be summarized as follows: (1) coaxial tubing systems exhibit a remarkably higher flow-dependent pressure gradient compared with conventional tubing systems; (2) in spontaneously breathing volunteers, additional work of breathing is highest with coaxial tubing systems; and (3) the breathing resistance was perceived to be highest in coaxial tubing systems.
This study confirms our hypothesis that the flow-dependent resistance of new coaxial tubing systems is substantially higher compared with systems composed of 2 separate tubes. The coaxial systems' disproportionally high resistance may be caused by their geometry. It is well known that the cross-sectional area determines a tube's resistance. ${ }^{6}$ Typically, the endotracheal tube represents the narrowest component of the artificial airways and hence the highest resistance to air flow. Accordingly, the pressure-flow characteristics of endotracheal tubes have been studied extensively, and Rohrer's equation has been well evaluated in this regard.2,7 By contrast, breathing tubes have relatively large cross-sectional areas; therefore, one would expect only marginal contribution to artificial airway resistance. Our results, however, demonstrate that this 

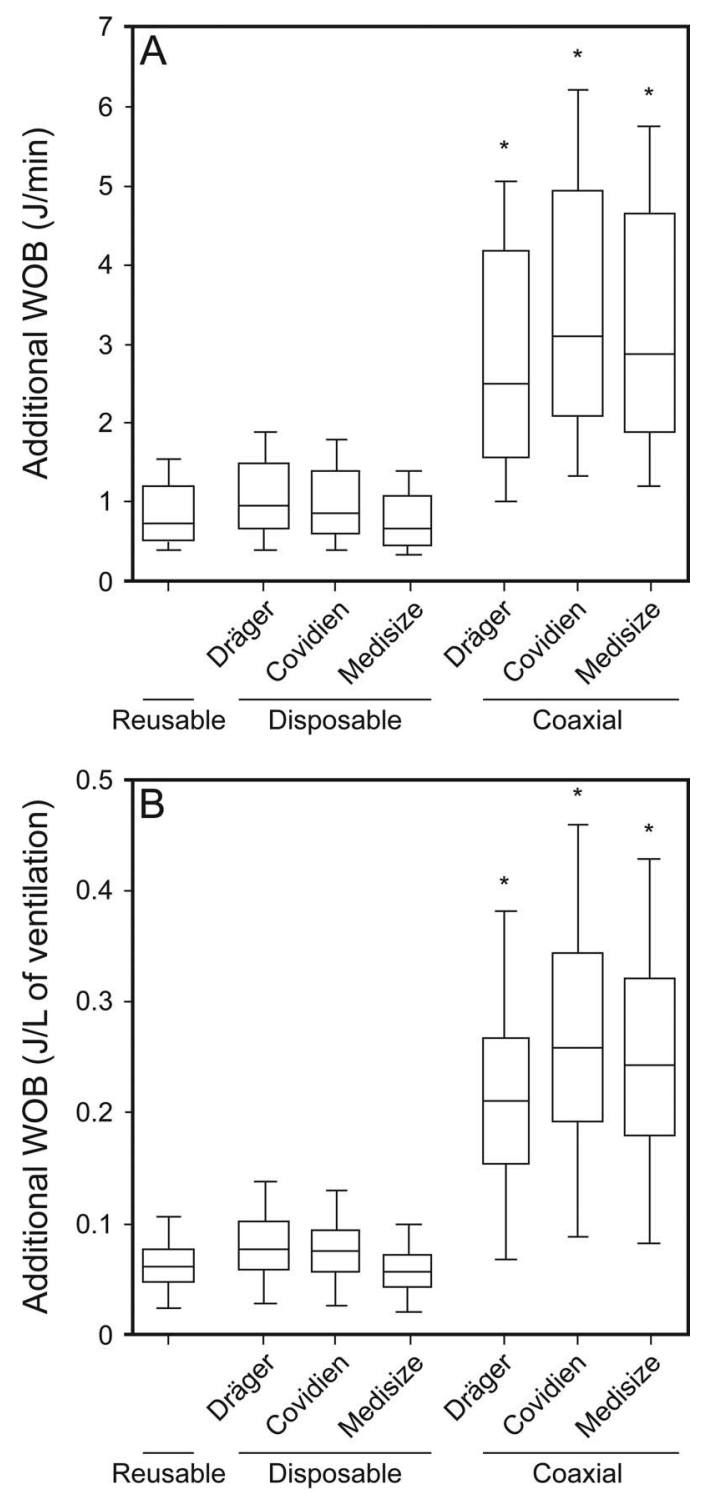

Fig. 4. Comparison of additional work of breathing (WOB) (A) and additional WOB/L of ventilation (B) across the different types of tubing systems (conventional reusable, conventional disposable, and coaxial tubing system) and different manufacturers. Boxes show interquartile range, horizontal lines denote medians, and whiskers show the minima and maxima. ${ }^{*} P<.001$ versus conventional reusable and disposable tubing systems.

is only true for conventional tubing systems and particularly not for coaxial ones. Integration of the inspiratory lumen into the expiratory one in coaxial tubing systems is at the expense of both luminal sectional areas. Whereas the sectional areas of conventional tubing systems comply with the ISO standard of a 22-mm inner diameter, the net sectional area of coaxial systems is considerably lower, only an approximately $16-\mathrm{mm}$ diameter. Despite marginal differences, this was comparable among all manufacturers. As a consequence, the coaxial tubes caused about two thirds of the resistance of an endotracheal tube with an 8.0-mm inner diameter. ${ }^{2}$

In our study, coaxial tubing systems showed the highest pressure gradient during expiration, which may be attributable to the tube's expiratory limb's greater length. This finding should call attention to patients presenting with expiratory flow limitation. During passive expiration, the respiratory systems' elastic recoil forces and total airway resistance determine the time required for complete exhalation. High artificial airway resistance, as caused by the coaxial tubing systems, may prolong expiratory time, thus promoting incomplete expiration and emergence of intrinsic PEEP. ${ }^{8}$

Although we found significantly higher resistances across disposable compared with reusable conventional tubing systems in 2 manufacturers, this difference was of minor clinical relevance. Both systems showed comparable geometries but varying properties of their tubes' inner surfaces. Disposable tubing systems (as well as coaxial tubing systems) are fabricated from thin plastic. This requires a corrugated texture of the material to ensure flexibility and stability at the same time. However, one can assume that the riffled surface promotes turbulent flow, ${ }^{9}$ which increases resistance. Our data support this assumption. Turbulent flow profiles prevailed in all tubing systems to different extents. This becomes evident by the nonlinear dependence of $\Delta \mathrm{P}$.

The high resistance of coaxial tubing systems was associated with a high additional WOB during spontaneous breathing. In a previous study including anesthetized, intubated, and spontaneously breathing subjects, total $\mathrm{WOB} / \mathrm{L}$ of ventilation was found to amount to about $1 \mathrm{~J} / \mathrm{L} .^{5}$ According to our results, a conventional tubing system would have contributed nearly $10 \%$ to the total WOB in those subjects. However, under the same assumptions, a coaxial tubing system would cause about $25 \%$ of the total WOB/L.

Pressure support ventilation may partly compensate for the additional WOB caused by coaxial tubing systems. Pressure support ventilation provides constant pressure support in inspiration, thereby inevitably leading to undercompensation or overcompensation of the airways' resistance, depending on the actual flow. ${ }^{10}$ However, to roughly compensate for the additional WOB, the amount of additional pressure support may correspond to $\Delta \mathrm{P}_{600}$.

The higher additional WOB caused by a coaxial tubing system compared with a conventional one requires a larger breathing effort. Consequently, our volunteers rated the resistance of breathing via a coaxial tubing system higher than the resistance of breathing via a conventional tubing system. Whereas the healthy volunteers are likely to be able to tolerate this additional WOB, the patient with an impaired respiratory system may fail to do so. In this regard, the conventional tubing system clearly performs better. 


\section{Airway Resistance and WOB With Coaxial Tubing}

It has to be noted that we have calculated additional WOB from the pressure-flow characteristics of the respective tubing system and the flow that was generated by the volunteers during breathing without a connected device. We omitted the direct measurement while breathing through the respective device for reasons of comparability between the investigated situations. First, we wanted to eliminate effects of breathing variability during the different trials. Second, we wanted to prevent adaptation of the breathing pattern in response to the demanded work of breathing.

\section{Conclusions}

In summary, all elements of the breathing circuit contribute to artificial airway resistance. Conventional tubing systems contribute to airway resistance only to a minor extent. By contrast, coaxial tubing systems contribute to airway resistance to a relevant extent. Based on these findings, we suggest applying coaxial tubing systems carefully with regard to their increased resistance.

\section{REFERENCES}

1. Baum J, Züchner K, Hölscher U, Sievert B, Stanke HG, Gruchmann T, Rathgeber J. Climatization of anesthetic gases using different breathing hose systems. Anaesthesist 2000;49(5):402-411.
2. Guttmann J, Eberhard L, Fabry B, Bertschmann W, Wolff G. Continuous calculation of intratracheal pressure in tracheally intubated patients. Anesthesiology 1993;79(3):503-513.

3. Guttmann J, Kessler V, Mols G, Hentschel R, Haberthür C, Geiger K. Continuous calculation of intratracheal pressure in the presence of pediatric endotracheal tubes. Crit Care Med 2000; 28(4):1018-1026.

4. Schumann S, Stahl CA, Möller K, Priebe HJ, Guttmann J. Moisturizing and mechanical characteristics of a new counter-flow type heated humidifier. Br J Anaesth 2007;98(4):531-538.

5. Brochard L, Rua F, Lorino H, Lemaire F, Harf A. Inspiratory pressure support compensates for the additional work of breathing caused by the endotracheal tube. Anesthesiology 1991;75(5):739-745.

6. Bock KR, Silver P, Rom M, Sagy M. Reduction in tracheal lumen due to endotracheal intubation and its calculated clinical significance. Chest 2000;118(2):468-472.

7. Spaeth J, Steinmann D, Kaltofen H, Guttmann J, Schumann S. The pressure drop across the endotracheal tube in mechanically ventilated pediatric patients. Paediatr Anaesth 2015;25(4):413-420.

8. Rossi A, Polese G, Brandi G, Conti G. Intrinsic positive endexpiratory pressure (PEEPi). Intensive Care Med 1995;21(6):522536 .

9. Jimenez J. Turbulent flows over rough walls. Annu Rev Fluid Mech 2004;36(1):173-196.

10. Mols G, von Ungern-Sternberg B, Rohr E, Haberthür C, Geiger K, Guttmann J. Respiratory comfort and breathing pattern during volume proportional assist ventilation and pressure support ventilation: a study on volunteers with artificially reduced compliance. Crit Care Med 2000;28(6):1940-1946. 